shear walls by Barda $(7,8)$ appear to confirm the author's approach. Under horizontal load reversals no yielding was observed in the vertical flange steel, while distributed vertical web reinforcement reached yield at loadings near the ultimate shear strenath of the walls and was effective in contributing to the level of shear resistance sustained, principally by maintaining equilibrium of web strut elements by resisting overturning (Element 2 in the paper). Barda found that horizontal and vertical web reinforcement were effective in producing a well-distributed crack pattern and in controlling crack widths. Parallel cracks at inclinations between 37 and 43 degrees formed a series of web struts which sustained very high compressive forces (equilibrated by adequately designed vertical web bars) in transferring shear through the web to the base.

In reversals of horizontal loading increased gradually up to the ultimate shear strength of the wall, a proportion of the total shear appears to have been resisted by the contribution of the concrete. After reaching ultimate, the load-carrying capacity in shear decreased during subsequent reversals, presumably due to progressive degradation of concrete mechanisms (e.g., aggregate interlock). This decrease may have been relatively rapid in some test walls but little information has been published on this phase of wall performance. When fully developed, web struts depend. upon the overturning resistance provided by distributed vertical web reinforcement for their continued effectiveness in transmitting shear forces. Therefore, this author considers that until further test information is available, distributed web reinforcement should be provided to resist the full code specified seismic loading without reliance upon the contribution of the concrete.

The intermediate group of catecory 6 shear walls covering the range / $\leqslant h w / 1 \mathrm{w}<2$ includes a variety of practical wall cases, e.g., with or without substantial flanges or significant axial loads, and consequently the mode of earthquake resistance may vary considerably. Either a shear mode (i.e., diagonal web cracking) or ductile flexural yielding of tension reinforcement may dominate behaviour, or both mechanisms may combine to share in seismic energy dissipation. Since actual behaviour is difficult to predict reliably, the code requirement that all these walls be detailed to adequately control diagonal web cracking at code lateral loads coriesponding to $S=.1 .6$ should ensure acceptable performance of the wall in respect of contribution of the shear mode.

In some intermediate shear walls it appears likely that, notwithstanding extensive controlled web cracking, the principal energy dissipating mechanism may be that of yielding of flange reinforcement near the base. Since this behaviour would be very similar to that of tall ductile shear walls, a correspondingly similar capacity design approach is suggested so as to ensure that the principal energy dissipating mechanisms should be maintained in a stable manner and are not precluded by non-ductile failure mechanisms. For example, in a wall of rectangular section with low axial load where designed cantilever moment and web shear steel have comparable resistance, the contribution of concrete may enhance diagonal web shear resistance and cause the base section to hinge at flexural capacity. However this in turn could result in early failure due to sliding shear, a situation which could be predicted and corrected if capacity checks were made during design.

Intermediate wall cases where such ductile hinging is likely to be attainable may be relatively few. Capacity design checks referred to by Mr. Williams are suggested only for these cases, and such checks should involve only a minor amount (if any) of additional horizontal web reinforcement in the base area. The standard of design remains at the level required by the code $(S=1.6)$, and hence concern regarding undue conservatism should be removed.

The passage relating to coupled shear walls quoted by Mr. Williams is not a suggestion by the author, but reflects a particular code requirement ( $\mathrm{Cl}$. 3.3.4.I and commentary). It is part of a discussion on code intent based on the commentary and reference (3). Mr. Williams' contribution, contrary to the present code requirement, is a discussion on the code itself and is understood to be the subject of recent analytical studies by the University of Canterbury.

From the particular stand-point of the code, using available background information, the seminar paper attempted to elucidate some design aspects of the code provisions and intent. More detailed guidelines on strength design and capacity design of shear walls have yet to be formulated to resolve areas of uncertainty. The author thanks Mr. Williams for his contribution and is appreciative of the opportunity to clarify aspects of the paper including tests on low shear walls.

\section{ADDITIONAL REFERENCE}

8. Barda, F., Hanson, J. M. and Corley, W. G., "An Investigation of the Design and Repair of Low-Rise Shear Walls." Fifth World Conference on Earthquake

Engineering (Session 3A), Rome, 1973.

\section{MOMENT REDISTRIBUTION IN CONTINUOUS B EAMS OF EARTH- QUAKE RESISTANT MULTISTOREY REINFORCED CONCRETE FRAMES“ - T. Paulay}

Bulletin of N.Z. National Society fcr Earthquake Engineering, Vol. 9, No. 4, December, 1976.

\section{R. L. WILLIAMS}

Professor Paulay has made an interesting and worthwhile contribution to the art of moment redistribution, a subject of increasing importance in ductile reinforced concrete moment resisting frames where equalisation of top and bottom steel in the beam at plastic hinges has been shown to significantly improve their performance under cyclic loading.

Professor Paulay however omits to show the next logical step of capacity design. That is to adjust his diagram so that it 
passes through the desired plastic hinge at the level equal to the ideal strength of the beam with the reinforcement actually provided at that point. The resultant diagram would then represent the worst possible moments that could be applied to the beam between the plastic hinges under any loading and is ideal for establishing reinforcement at cut off points, etc.

Perhaps Professor Paulay would like to comment on the procedure used in our office which included this step as illustrated below. (See accompanying diagram, Figure A.)

\section{Step 1} cases

Establish beam and moments for load

$$
\begin{array}{ll}
\text { 1. } & 1.4 D+1.7 L r \\
\text { 2. } & D+1.3 L r \pm E \\
\text { 3. } & 0.9 D \pm E
\end{array}
$$

At this stage it is not necessary to draw moment diagrams between supports.

\section{Step 2}

Reduce negative beam end moments by up to $15 \%$ at end supports and supports and up to $30 \%$ for internal supports.

\section{Step 3}

From reduced moment points draw lines parallel to end moment line for cases.9D \pm $E$ and $D+1.3 \mathrm{Lr} \pm \mathrm{E}$

\section{Step 4}

Design steel at faces of column if this is the desired location of the plastic hinge, and establish ideal moment at these points. Establish dependable moments on the diagram.

\section{Step 5}

Draw free movement diagrams .9D and $\mathrm{D}+1.3 \mathrm{Lr}$ between opposite dependable moments.

\section{Step 6}

Superimpose 1.4D + 1.7Lr diagram over above diagram with adjustment downwards to ideal moment downwards at support if this amount is greater.

The resulting diagram should cover all feasible moments in the beam under any capacity condition and should be used in detail beam cut off steel etc.

\section{T. PAULAY}

The suggestions of Mr. Williams will be appreciated by designers, for they are extensions of the procedure presented in the paper and indeed they are necessary to complete the full design of a beam. The purpose of the paper was only to introduce an acceptable and simple technigue of moment redistribution in beams of reinforced concrete ductile frames.

The author believes that it is a little easier to manipulate with a set of straight lines rather than with a set of curves, as shown in Fig. 4 of the paper, and for this reason it is suggested that the design steps used by Mr. Williams may be also carried out as follows:

(a) When moment redistribution has been applied to the beams, such as shown for the example structure presented in the paper, design envelopes for the required dependable moments are obtained, as aiven in Fig. 4(b). This figure is reproduced in Fig. B where additional information is also shown. The requirements for dependable moment capacities are shown by the fully shaded area.

(b) The designer may now proceed with the proportioning of the beam. Having completed the detailing of the critical sections, for the purpose of shear and column design, the flexural overcapacity of the potential plastic hinges will need to be determined. These moments should not be less than 1.25/ $0.9=1.39$ times those resulting from the shaded envelopes of Fig. B. As an illustration the overcapacity plastic hinge moments, that are assumed to have resulted in the example structure, are \pm 130 moment units at the face of column $A$ and -155 units at the faces of column B. The extension of overcapacity moment base lines $\overrightarrow{\mathbb{V}} \mathrm{E}$ and $\mathrm{M}_{O}^{\mathrm{E}}$ to the column centre lines may be used subsequently in determining the overstrength factors required for computing the column design moments $(3)$

(c) The curtailment of the beam flexural reinforcement may now be determined to ensure that nowhere else along the beam can yield occur when the selected plastic hinge moments develop. It will be seen that moment envelopes corresponding with overstrenath hinge capacities, developed simultaneously in a span, $\left(\mathrm{M}_{0}^{\mathrm{E}}\right)$ may give unconservative moments in the midspan regions of that span. Therefore for this purpose it may be more appropriate to assume that when the overstrength of one plastic hinge is being developed in a span, only the ideal flexural strenath (i.e. $1 / 1.25=$ 0.8 times the overstrength) is simultaneously induced in the other hinge of that span. The partiy shaded envelopes, shown by the straight dashed lines in Fio. B, may then be used for the curtailment of the flexural reinforcement.

\section{ADDITIONAL REFERENCE}

(3) Paulay, T., "Columns-Evaluation of Actions", Bulletin of the New Zealand National Society for Earthquake Engineering, Vol. 10, No. 2, June, 1977. 




FIGURE A: MOMENT REDISTRIBUTION FOR BEAMS USING CAPACITY DESIGN

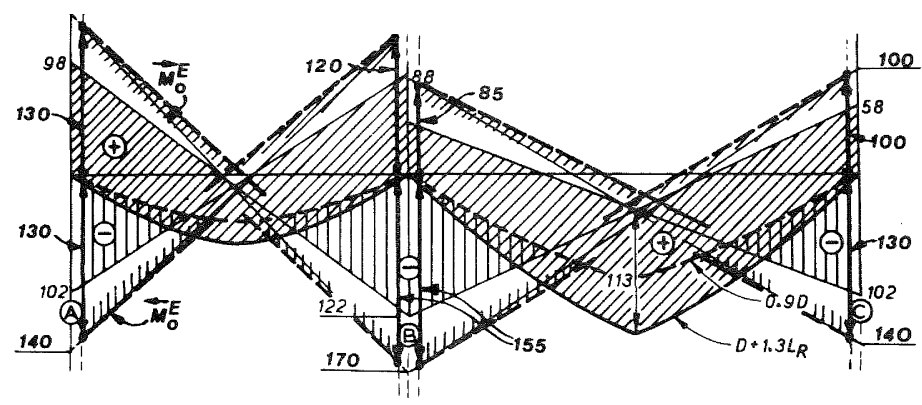

FIGURE B: DESIGN MOMENT ENVELOPES AND FLEXURAL OVERCAPACITY ENVELOPES 